\title{
Do edifício ao bairro: critérios de certificação de sustentabilidade e eficiência energética no planejamento de bairros ativos
}
From building to neighborhood: criteria for sustainability certification and energy efficiency in planning active neighborhoods

Del edificio al barrio: criterios para certificación de sostenibilidad y eficiencia energética en la planificación de barrios activos

\author{
Fernando Luís de Oliveira Costa \\ Mestrando, UNINOVE, Brasil. \\ arquitetura2050@gmail.com
}

Alexandre de Oliveira e Aguiar Professor Doutor, UNINOVE, Brasil. aaguiar@uni9.pro.br 

Ferramentas de avaliação da sustentabilidade em edifícios têm sido utilizadas mundialmente como um guia indicativo do seu desempenho, através da coleta e interpretação de um número de indicadores de desempenho (GIBBERD, 2001).

A Certificação Leadership in Energy and Enviromental Design (LEED) é um exemplo desse tipo de ferramenta, que é utilizada na Construção Civil e que funciona para todos os tipos de edifícios, podendo ser aplicada a qualquer momento no empreendimento.

Os projetos que buscam a certificação LEED são analisados por 7 dimensões. Todas elas possuem pré-requisitos (práticas obrigatórias) e créditos (recomendações) que, à medida que são atendidos, garantem pontos à edificação.

Os níveis da certificação podem ser Certified, Silver, Gold e Platinum e são definidos conforme a quantidade de pontos adquiridos, podendo variar de 40 a 110 pontos.

No Brasil, já se pode contar com um programa orientador do desenvolvimento de cidades sustentáveis que possui diversos indicadores de sustentabilidade, dentre eles, nove itens que compõem uma categoria voltada exclusivamente ao Planejamento e Desenho Urbano.

Nessa categoria existe, por exemplo, um indicador formado pelo percentual de edifícios novos e reformados que têm avaliação em termos de critérios de sustentabilidade, frente ao número total de edifícios e projetos de reforma (edifícios de propriedade ou incorporação municipal) no ano anterior (Programa Cidades Sustentáveis, 2012).

Há outra ferramenta de avaliação e certificação de desempenho de edifícios, desenvolvida na Alemanha e que é bem mais utilizada em países europeus, até o presente momento, mas que é bastante similar ao LEED e que será abordada com detalhes durante este trabalho. Trata-se do Sistema Deutsche Gesellschaft für Nachhaltiges Bauen (DGNB), uma ferramenta de planejamento com controles de qualidade transparentes e precisos.

\section{OBJETIVO}

O objetivo deste artigo é discutir os elementos de uma estrutura potencial para abordar a sustentabilidade de ambientes urbanos no nível de bairros, utilizando-se, como base, os critérios de certificação de sustentabilidade e eficiência energética de edifícios.

\section{JUSTIFICATIVA}

Esta discussão pode contribuir para a construção de cidades mais igualitárias e com melhor qualidade de vida, já que o presente estudo poderá indicar alternativas para planejamento urbano mais inteligente, certificações ambientais de edifícios mais próximas do contexto regional brasileiro e melhores práticas de eficiência energética aplicáveis à tecidos urbanos.

\section{REVISÃO BIBLIOGRÁFICA}

Rogers (2008) argumenta que uma cidade sustentável precisa ser compacta, densa e com diversidade de usos, de modo que a pressão da mancha urbana sobre a cobertura vegetal, 
recursos hídricos e áreas rurais seja diminuída. Kenworthy (2006) reforça esse conceito e acrescenta a necessidade de elas oferecerem áreas verdes, cultura, lazer, transporte público coletivo e não motorizado, bem como empregos decentes, diminuindo os impactos da expansão da mancha urbana sobre as áreas rurais e a cobertura vegetal, bem como as interferências em corpos d'água.

A construção de edifícios assume, nesse contexto, um papel essencial em atender, ao mesmo tempo, as demandas de uso da cidade e a necessidade de se manter a qualidade ambiental.

Assim, foram desenvolvidas, desde a década de 1990, algumas ferramentas capazes de avaliar o nível efetivo de sustentabilidade de cada edificação, permitindo uma comparação entre elas e evidenciando-se aquelas que têm um comportamento quantitativo superior às demais e que devem, por isso, ser valorizadas (FERREIRA et al., 2012). Em 1990, na Inglaterra, surge o primeiro sistema a oferecer um selo ambiental para edifícios, conhecido como Building Research Establishment Environmental Assessment Method (BREEAM).

Depois do BREEAM diversos outros sistemas surgiram mundialmente, tendo como objetivo comum a todos eles a avaliação quantificável e compreensiva das características de sustentabilidade de um dado edifício, ou empreendimento, baseando-se num conjunto de critérios que visam o melhor desempenho, o embasamento para tomada de decisão em relação aos impactos ambientais e a sua potencialidade de melhoria (FERREIRA et al., 2012).

O LEED, ou Leadership in Energy and Environmental Design, criado em 1998, pelo The U.S. Green Building Council (USGBC), nos Estados Unidos, funciona para todos os edifícios e pode ser aplicado a qualquer momento no empreendimento.

Os projetos que buscam a certificação LEED são analisados por 7 critérios: espaço sustentável; eficiência do uso da água; energia e atmosfera; materiais e recursos; qualidade ambiental interna; inovação e processos e créditos regionais (STEFANUTO; HENKES, 2012). Todos os critérios possuem pré-requisitos (práticas obrigatórias) e créditos (recomendações) que, à medida que são atendidos, garantem pontos à edificação.

Hoje em dia, o USGBC divulga dados de edificações certificadas por meio do portal GBIG (http://www.gbig.org). Nele é possível conhecer dados numéricos dos critérios do LEED e o nível de certificação alcançado para qualquer edificação já certificada, ou com processo de certificação em andamento. Além disso, também já se encontra em utilização outro aparato tecnológico, disponibilizado pelo mesmo USGBC, que avalia em tempo real a performance de edifícios - que já têm certificação ou que ainda não têm e desejam ter - quanto à 5 critérios específicos, que são: energia, água, resíduos, transporte e experiência humana. Trata-se da Plataforma ARC, na qual se pode inserir dados de performance de uma determinada edificação (como consumo de energia e água, por exemplo) e comparar o histórico desta com médias locais e globais, permitindo que, por meio da análise desses dados, seja possível efetuar melhorias na gestão do empreendimento. 
Outra ferramenta de avaliação e certificação de performance de edifícios é o Sistema DGNB, mais utilizada em países europeus (até o momento) e de origem alemã. Assim como o LEED, o Sistema DGNB também tem a intenção de oferecer meios para um planejamento mais apropriado, tanto na gestão de empreendimentos em operação, quando no projeto e construção de novos. O DGNB avalia os edifícios e empreendimentos por meio de 6 critérios que, embora possuam pesos diferentes quando comparados ao LEED, são, na realidade, bastante semelhantes. Os seis critérios são: qualidade ambiental, qualidade econômica, qualidade sociocultural e funcional, qualidade técnica, qualidade de processos e qualidade do local.

A Tabela 1 apresenta uma comparação entre BREEAM, LEED e DGNB, considerando as áreas de enfoque das avaliações e os pesos correspondentes a essas áreas, para cada certificação.

Tabela 1: Pesos das áreas dos três sistemas

\begin{tabular}{lccc}
\hline \multicolumn{1}{c}{ Áreas / categorias } & BREEAM Ecohomes & LEED for Homes & DGNB \\
\hline Localização + uso do solo & $12 \%$ & $12,7 \%$ & $5,5 \%$ \\
Energia + atmosfera & $28,4 \%$ & $27,2 \%$ & $13,5 \%$ \\
Água & $10 \%$ & $14,5 \%$ & $2,3 \%$ \\
Materiais + resíduos sólidos & $14 \%$ & $8,2 \%$ & $1,1 \%$ \\
Outros recursos impactantes & - & - & $3,4 \%$ \\
Conforto e saúde & $14 \%$ & $16,4 \%$ & $18,6 \%$ \\
Gestão & $8 \%$ & $1,8 \%$ & $19 \%$ \\
Amenidades & $4 \%$ & $0,9 \%$ & 1 \\
Transportes e mobilidade & $4 \%$ & $7,3 \%$ & $4 \%^{1}$ \\
Outros aspetos sociais & $5,6 \%$ & $7,3 \%$ & $10,1 \%^{1}$ \\
Aspetos unicamente econômicos & - & $3,6 \%{ }^{2}$ & $22,5 \%$ \\
\hline
\end{tabular}

1. Inclui outros critérios não avaliados para a classificação global na vertente "Qualidade do Local";

2. Possibilidade de consideração nos critérios da categoria "Prioridade Regional".

Fonte: Adaptado de Ferreira et al., 2012.

Relativamente aos pesos das diferentes áreas, verifica-se que a mais importante, nos três sistemas, é Energia e Atmosfera, seguida por Conforto e Saúde. Estas são as áreas onde parece haver um senso comum entre os sistemas de certificação apresentados anteriormente, o que pode sinalizar um caminho interessante no que diz respeito à utilização das certificações de edifícios em análises ligadas ao contexto de vizinhanças ou bairros.

Não são muitos os pesquisadores que já escreveram sobre a utilização de algum tipo de métrica confiável para avaliar as características dos ambientes construídos - em termos de eficiência e 

urbano (LE GUEN et al., 2018). Por meio dos estudos de Tam et al. (2018), Garau e Pavan (2018) e Le Guen et al. (2018) percebe-se que, quando se pretende discutir a sustentabilidade, relacionando-se determinados edifícios ao contexto urbano onde estão inseridos, a questão da eficiência energética é um ponto marcante e que atuará como fio condutor dessa discussão.

Verovsek, Juvancic e Zupancic (2015), por exemplo, relataram sua experiência na formulação de um instrumento previsto para avaliar o desempenho da sustentabilidade em alguns bairros selecionados em cidades da Eslovênia. Os autores trabalharam com 5 categorias cruciais para a criação de uma ferramenta de análise: eficiência energética, eficiência ambiental, eficiência espacial urbana, relações com a comunidade (em termos de hábitos de consumo, tomadas de decisões e iniciativas comunitárias) e exploração de soluções inteligentes de Tecnologias de Informação e Comunicação para auxiliar as outras quatro categorias anteriores.

Esse instrumento abrange uma abordagem mais holística em metodologias de avaliação e se estende à escala do bairro, abrangendo não apenas a questão residencial, mas, também, econômica e funcional.

$\mathrm{Na}$ análise proposta por Verovsek et al. (2015), cada uma das categorias já mencionadas é observada através de 3 níveis estratégicos de implementação, que são: as edificações; os espaços públicos e os espaços abertos e o transporte e infraestruturas de mobilidade, como se pode observar no Quadro 1. 
Quadro 1: Categorias de avaliação através dos três assuntos relevantes de adaptação em bairros

\begin{tabular}{|c|c|c|c|}
\hline & Edificações & $\begin{array}{l}\text { Espaços Públicos e } \\
\text { Espaços Abertos }\end{array}$ & $\begin{array}{c}\text { Transporte e Infraestrutura de } \\
\text { Mobilidade }\end{array}$ \\
\hline $\begin{array}{l}\text { Eficiência } \\
\text { Energética }\end{array}$ & $\begin{array}{l}\text { Aquecimento, sistemas de } \\
\text { ventilação e ar condicionado }\end{array}$ & $\begin{array}{l}\text { Orientação dos espaços, } \\
\text { exposição à luz solar, ilhas } \\
\text { de calor, sombras }\end{array}$ & $\begin{array}{l}\text { Demanda, modais disponíveis, } \\
\text { uso do transporte público, } \\
\text { infraestrutura }\end{array}$ \\
\hline $\begin{array}{l}\text { Eficiência } \\
\text { Ambiental }\end{array}$ & $\begin{array}{l}\text { Manutenção de áreas } \\
\text { verdes, gestão das águas e } \\
\text { esgotos, uso de energia } \\
\text { limpa }\end{array}$ & $\begin{array}{l}\text { Uso de energia limpa, } \\
\text { gestão de resíduos, gestão } \\
\text { das águas. }\end{array}$ & $\begin{array}{l}\text { Uso de recursos fósseis, uso de } \\
\text { energia limpa, demanda, } \\
\text { emissões de gases. }\end{array}$ \\
\hline $\begin{array}{l}\text { Eficiência } \\
\text { Espacial } \\
\text { Urbana }\end{array}$ & $\begin{array}{l}\text { Uso e organização do espaço, } \\
\text { gestão de questões e valores } \\
\text { culturais. }\end{array}$ & $\begin{array}{l}\text { Uso e organização do } \\
\text { espaço, gestão de questões } \\
\text { e valores culturais, } \\
\text { preservação da identidade } \\
\text { do local. }\end{array}$ & $\begin{array}{l}\text { Organização do tráfego, } \\
\text { acessibilidade, tráfego de } \\
\text { pedestres e bicicletas. }\end{array}$ \\
\hline $\begin{array}{l}\text { Relações com } \\
\text { a Comunidade }\end{array}$ & $\begin{array}{l}\text { Hábitos de consumo em } \\
\text { relação a equipamentos } \\
\text { domésticos, crenças e } \\
\text { entendimentos em relação } \\
\text { ao meio ambiente }\end{array}$ & $\begin{array}{l}\text { Organização da } \\
\text { comunidade, decisões e } \\
\text { iniciativas comunitárias, } \\
\text { educação e aprendizado da } \\
\text { comunidade. }\end{array}$ & $\begin{array}{l}\text { Hábitos de viagens, propriedade } \\
\text { de veículos, hábitos de uso do } \\
\text { transporte público e tomada de } \\
\text { decisão. }\end{array}$ \\
\hline $\begin{array}{l}\text { Tecnologias } \\
\text { Inteligentes }\end{array}$ & $\begin{array}{l}\text { lluminação inteligente, uso } \\
\text { de sensores a aplicativos } \\
\text { para gestão de consumos. }\end{array}$ & $\begin{array}{l}\text { lluminação inteligente, uso } \\
\text { de sensores a aplicativos } \\
\text { para gestão de consumos e } \\
\text { para informações sobre } \\
\text { emissões. }\end{array}$ & $\begin{array}{l}\text { Sistemas viários e logística de } \\
\text { transportes com TICs, aplicativos } \\
\text { para caronas, compartilhamento } \\
\text { de veículos e uso de bicicletas. }\end{array}$ \\
\hline
\end{tabular}

Fonte: Adaptado de Verovsek et al., 2015

As 5 categorias e os 3 níveis estratégicos formam um sistema modular de indicadores, por meio do qual é possível identificar os sistemas que afetam as capacidades ambientais, a vitalidade econômica ou a qualidade da habitação. O passo seguinte na pesquisa desses autores é a criação de um índice de desempenho de sustentabilidade que permitirá, uma vez que seja monitorado, a comparação do desenvolvimento em termos de eficiência e uso racional de recursos.

Observa-se que, no tocante à Eficiência Energética no nível estratégico de Espaços Públicos e Espaços Abertos, a temperatura externa começa a ser investigada, levando-se em conta a sua elevação devido às propriedades dos pavimentos e à permeabilidade do solo (efeito llha de Calor).

No Brasil Marins (2016) desenvolveu uma análise comparativa entre um bairro planejado para ser sustentável no Brasil e um outro, com os mesmos conceitos, na Alemanha. Para isso, a autora também utilizou alguns parâmetros e indicadores que considerou importantes para a identificação das principais estratégias de promoção da sustentabilidade em projetos de desenvolvimento urbano as quais são: governança, morfologia urbana, mobilidade e acessibilidade urbanas, eficiência energética e suprimento de energia. Marins (2016) ressalta em suas conclusões a importância de se investir em desenho e projeto urbano, buscando definir 

Nesse sentido, parece ser um pressuposto razoável que haja uma influência de edifícios certificados na temperatura do entorno, possivelmente com amenização dos efeitos de ilhas de calor e nas possibilidades de modais de transporte mais sustentáveis. Com o tempo e o avanço do número de edifícios certificados, poderão ser coletadas evidências empíricas adicionais para confirmar esse pressuposto.

Uma estrutura potencial para análise da questão energética na sustentabilidade de bairros deve incluir aspectos que vão do projeto e operação do edifício (como orientação espacial, ventilação, condicionamento de ar e iluminação), até a interação com a vizinhança: modais de transporte e a organização de espaços físicos no edifício e no seu entorno, que permitam acesso por modais coletivos, não motorizados ou veículos compartilhados.

Finalmente, pode-se incluir em pesquisas futuras a possibilidade de que a avaliação de sustentabilidade e eficiência energética dos edifícios ocorra de forma isolada num primeiro momento, porém, será a partir da análise do conjunto de um aglomerado de edifícios que surgirão parâmetros para auxiliar na escolha de melhores estratégias aos tomadores de decisão do planejamento urbano.

\section{REFERÊNCIAS BIBLIOGRÁFICAS}

DONGHWAN, Gu; YONG, Kim Hwan; HYOUNGSUB, Kim. LEED, its efficacy in regional context: Finding a relationship between regional measurements and urban temperature. Energy and Buildings, v. 86, 2015. p. 687-691

FERREIRA, Joaquim; PINHEIRO, Manuel Duarte; BRITO, J. Comparação das ferramentas nacionais de avaliação da sustentabilidade na construção com o BREEAM e o LEED - uma perspetiva energética. Engenharia Civil Um, Braga, v. 43,2012 . p. 5-27.

GARAU, Chiara; PAVAN, Valentina Maria. Evaluating urban quality: indicators and assessment tools for smart sustainable cities. Sustainability, v. 10, n. 3, 2018. p. 575.

GIBBERD, Jeremy. The sustainable building assessment tool - assessing how buildings can support sustainability in developing countries. Continental shift, 2001. p. 11-14.

GIBBERD, Jeremy. Building systems to support sustainable development in developing countries. Facilities Planning and Management, CSIR Building and Construction Technology, Pretoria, 2003.

GUERRA, Maria Eliza Alves; LOPES, Anaísa Filmiano Andrade. Programa cidades sustentáveis: o uso de indicadores de sustentabilidade como critério de avaliação do ambiente urbano. Periódico Técnico e Científico Cidades Verdes, v. 3, n. 7, 2015.

KENWORTHY, J. R. The eco-city: ten key transport and planning dimensions for sustainable city development. Environment and Urbanization, v. 18, n. 1, p. 67-85, 4 jan. 2006.

LE GUEN, Morgane et al. Improving the energy sustainability of a Swiss village through building renovation and renewable energy integration. Energy and Buildings, v. 158, 2018. p. 906-923. 


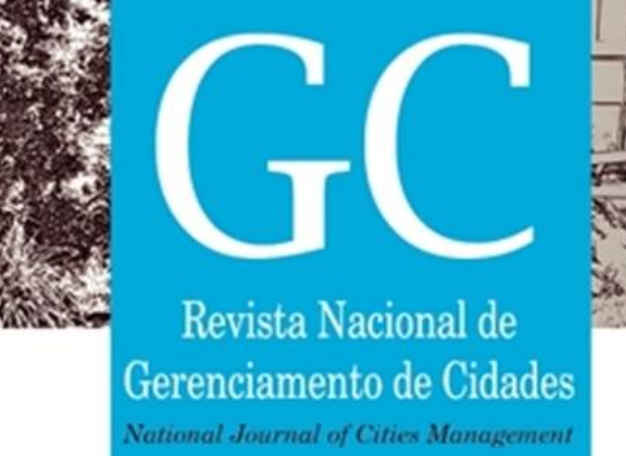

MARINS, Karin Regina de Casas Castro. Análise comparativa multicriterial de estratégias em sustentabilidade urbana aplicada aos bairros de Cidade Pedra Branca (Palhoça, SC) e Vauban (Freiburg, Alemanha). Ambiente Construído, v. 17, n. 1, 2017. p. 393-408.

OLIVEIRA, Matheus Henrique de. A bolha imobiliária e o caso do Brasil: uma breve discussão de possibilidades. 2013.

PROGRAMA CIDADES SUSTENTÁVEIS Indicadores. São Paulo. 2012. Disponível

em:

<http://www.cidadessustentaveis.org.br/>. Acesso em: Set. 2017.

ROGERS, R. E. G. Cidades para um pequeno planeta. Barcelona: Gustavo Gili, 2008.

SHIN, Min Ho et al. LEED, Its efficacy and fallacy in a regional context - an urban heat island case in California. Sustainability, v. 9, n. 9, 2017. p. 1674.

STEFANUTO, Ágata Pâmela Olivari; HENKES, Jairo Afonso. Critérios para obtenção da certificação LEED: um estudo de caso no Supermercado Pão de Açúcar em Indaiatuba/SP. Revista Gestão \& Sustentabilidade Ambiental, v. 1, n. 2, 2012. p. 282-332.

TANGUAY, Georges A. et al. Measuring the sustainability of cities: An analysis of the use of local indicators. Ecological Indicators, v. 10, n. 2, 2010. p. 407-418.

TAM, Vivian WY et al. Green neighbourhood: Review on the international assessment systems. Renewable and Sustainable Energy Reviews, v. 82, 2018. p. 689-699.

VEROVSEK, Spela; JUVANCIC, Matevz; ZUPANCIC, Tadeja. A vision of data-based decision support system in urban retroffiting from passive house to active neighbourhood. In: AEIT International Annual Conference (AEIT), 2015. IEEE, 2015. p. 1-6. 